\title{
PENGARUH MODEL PEMBELAJARAN TAI (TEAM ASSISTED INDIVIDUALIZATION) TERHADAP HASIL BELAJAR IPA DITINJAU DARI MOTIVASI BELAJAR PESERTA DIDIK SEKOLAH DASAR
}

\author{
Rizqy Amelia Ramadhaniyah Ahmad ${ }^{1}$,, Siti Aminah Mursalin ${ }^{2}$,, Julhidayat Muhsam³ \\ ${ }^{13}$ PGSD, Universitas Muhammadiyah Kupang \\ ${ }^{2}$ SD Inpres Cowang Terang Kab. Manggarai Barat \\ ${ }^{1}$ rizqy.ahmad92@gmail.com., ${ }^{2}$ sitiaminahmursalin7@ gmail.com, ${ }^{3}$ julhidayat.1.muhsam@ gmail.com
}

\section{INFO ARTIKEL}

Riwayat Artikel:

Diterima: 09-Januari-2021

Disetujui: 30-Maret-2021

\section{Kata Kunci:}

Team assisted

individualization, hasil

belajar, motivasi belajar

\section{ABSTRAK}

\begin{abstract}
Abstrak: Penelitian ini bertujuan untuk mengetahui pengaruh model pembelajaran team assisted individualization terhadap hasil belajar IPA ditinjau dari motivasi belajar siswa Kelas IV SD Inpres Cowang Terang. Sampel dalam penelitian ini berjumlah 42 orang yang dipilih dengan menggunakan teknik random sampling. Penelitian ini merupakan penelitian eksperimen semu dengan desain nonequivalent post test only control group design. Data hasil belajar dikumpulkan dengan menggunakan metode tes dengan instrumen tes pilihan ganda. Data motivasi belajar siswa dikumpulkan dengan metode non tes yakni kuesioner. Data hasil belajar yang diperoleh dianalisis dengan menggunakan teknik analisis statistik deskriptif dan ANAVA dua jalur. Hasil penelitian ini menunjukkan bahwa: (1) terdapat perbedaan hasil belajar IPA antara siswa yang dibelajarkan dengan model pembelajaran team assisted individualization dan siswa yang dibelajarkan dengan model pembelajaran konvensional, yang ditunjukkan oleh FA hitung $=8,22>\mathrm{F}$ tabel $=4,10$. (2) terdapat perbedaan hasil belajar IPA antara siswa yang memiliki motivasi belajar tinggi dan siswa yang memiliki motivasi belajar rendah, yang ditunjukkan oleh $\mathrm{FB}$ hitung $=4,36>\mathrm{F}$ tabel $=4,10$. (3) terdapat pengaruh interaksi model pembelajaran yang diterapkan dengan motivasi belajar terhadap hasil belajar IPA, yang ditunjukkan oleh FAB hitung $=38,17>\mathrm{F}$ tabel $=4,10$. Berdasarkan hasil penelitian, dapat disimpulkan bahwa model pembelajaran TAI berpengaruh secara signifikan terhadap hasil belajar IPA ditinjau dari motivasi belajar siswa sekolah dasar.
\end{abstract}

\begin{abstract}
Astract: This study aims to determine the effect of the team assisted individualization learning model on science learning outcomes in terms of learning motivation of fourth grade students of SD Inpres Cowang Terang. The sample in this study amounted to 42 people who were selected using random sampling technique. This research is a quasi-experimental study with a nonequivalent post test only control group design. Learning outcome data were collected using the test method with multiple choice test instruments. Student learning motivation data were collected using the non-test method, namely a questionnaire. The learning outcome data obtained were analyzed using descriptive statistical analysis techniques and two-way ANAVA. The results of this study indicate that: (1) there are differences in science learning outcomes between students who are taught using the team assisted individualization learning model and students who are taught using conventional learning models, which is shown by $F A$ count $=8.22>F$ table $=4.10$. (2) there are differences in science learning outcomes between students who have high learning motivation and students who have low learning motivation, which is shown by FB count $=4.36>F$ table $=4.10$. (3) there is an interaction effect of the learning model applied with learning motivation towards science learning outcomes, as indicated by the $F A B$ count $=38.17>F$ table $=4.10$. Based on the research results, it can be concluded that the TAI learning model has a significant effect on science learning outcomes in terms of learning motivation of elementary school students.
\end{abstract}

\section{A. LATAR BELAKANG}

Sekolah Dasar sebagai awal dari pendidikan formal, memiliki andil besar sebagai pondasi pengetahuan untuk kelanjutan pendidikan seseorang. Sudah seharusnya, sekolah dasar dapat memberikan pendidikan dan pengetahuan yang bermakna. Pengetahuan yang bermakna mampu memberikan pondasi yang kokoh bagi siswa. Selama proses pembelajaran, peranan guru selaku pendidik adalah membantu peserta didik agar dapat belajar dengan baik dan mudah. Siswa selaku peserta didik, berusaha untuk mencari informasi, memecahkan masalah, 
dan mengemukakan pendapatnya. Inti dari proses pendidikan adalah proses pembelajaran yang terjadi di dalam kelas. Jadi, perbaikan mutu pendidikan harus dimulai dengan menata dan meningkatkan kualitas pembelajaran di kelas. Proses pembelajaran yang berkualitas di kelas, dapat tercipta apabila siswa dan guru berperan aktif di dalamnya. Siswa dan guru berinteraksi dalam suatu kegiatan yang disebut dengan proses pembelajaran. Upaya mewujudkan proses pembelajaran yang efektif dan efisien adalah guru hendaknya mampu mewujudkan perilaku mengajar secara tepat. Artinya, guru harus mampu mewujudkan perilaku belajar siswa melalui interaksi pembelajaran yang efektif dalam proses pembelajaran yang kondusif.

Salah satu mata pelajaran di sekolah dasar yang menuntut kegiatan aktif siswa adalah Ilmu Pengetahuan Alam (IPA). Pembelajaran IPA, terutama di tingkat sekolah dasar harus mengacu pada tingkat perkembangan anak. Ilmu pengetahuan alam merupakan mata pelajaran yang memiliki kedudukan sangat penting dan harus di aplikasikan pada peserta didik dari jenjang sekolah dasar agar memberikan persediaan kepada peserta didik untuk mempunyai kemampuan berpikir kritis, menciptakan dan sistematis, serta memiliki kemampuan berkerja dalam tim (Muhsam, 2020). Trianto (2012) menyatakan bahwa IPA hakikatnya merupakan suatu produk, proses, dan aplikasi. Tujuan pendidikan sains adalah mencakup pengembangan ranah kognitif (pengetahuan), afektif (sikap dan nilai), dan psikomotor (ketrampilan), serta ranah interkonektif (perpaduan kedua ranah ini) (Zubaedi, 2011). IPA diharapkan sebagai sarana bagi siswa untuk mengetahui diri sendiri dan lingkungan sekitar, serta sebagai harapan untuk mengembangkan lebih lanjut dalam kehidupan sehari-hari (Trianto, 2014).

Rendahnya hasil belajar IPA disebabkan beberapa hal yaitu: (a) siswa kurang termotivasi dalam pembelajaran klasikal, dalam proses pembelajaran di kelas, (b) siswa yang pintar tidak mau mengajari teman yang kurang mampu memahami, (c) guru masih dominan menggunakan metode ceramah yang menyebabkan siswa menjadi pasif, dan cepat mengantuk dalam mengikuti pembelajaran karena proses pembelajaran didominasi oleh guru, (d) siswa kurang aktif dan kreatif dalam mengerjakan tugas yang diberikan guru, karena belum mengerti dan memahami materi dan tugas yang diberikan guru, (e) penggunaan metode kerja kelompok jarang digunakan, dan apabila digunakan juga kurang efektif, dikarenakan tidak semua siswa mau bekerjasama dalam kelompok, yang bekerja hanya siswa yang pintar saja, (f) kurangnya menggunakan media pembelajaran yang menarik bagi siswa, sehingga siswa merasa kesulitan memahami materi pelajaran yang disampaikan guru, (g) kemampuan siswa yang tidak sama di dalam kelas, proses pembelajaran masih didominasi oleh guru, siswa pasif dan hanya sebagai pendengar saja, (h) dalam pembentukan kelompok sering terjadi perselisihan, karena peserta didik cenderung memilih teman yang akan diajak berkelompok.

Masalah yang muncul di Kelas IV SD Inpres Cowang Terang, tidak terlepas dari peran guru di dalam proses belajar mengajar. Salah satunya adalah guru kurang kreatif dalam memilih model pembelajaran yang sesuai dengan karakteristik siswa. Penggunaan model pembelajaran yang kurang tepat mengakibatkan siswa menjadi kurang aktif dan kurang termotivasi dalam pembelajaran. Pembelajaran yang dilaksanakan lebih didominasi oleh guru yaitu dengan menerapkan metode ceramah. Pembelajaran yang didominasi guru akan mengurangi keaktifan siswa dalam menggali informasi terkait materi pelajaran. Siswa ditempatkan sebagai objek yang pasif dalam pembelajaran.

Untuk mengatasi problema tersebut peneliti menerapkan model pembelajaran TAI (team assisted individualization). Model pembelajaran tersebut, diharapkan mampu memberikan pembaruan terhadap pembelajaran, serta berpengaruh positif terhadap hasil belajar IPA peserta didik kelas IV di SD Inpres Cowang Terang. Model pembelajaran TAI merupakan penggabungan antara model pembelajaran kooperatif dengan model pembelajaran individual (Slavin, 2008). Model pembelajaran kooperatif tipe TAI merupakan penggabungan antara model pembelajaran individual dengan model pembelajaran kooperatif untuk memenuhi kebutuhan dari berbagai kelas yang berbeda (Slavin dalam Westport, 2009).

Dalam penerapan model pembelajaran team assisted individualization (TAI), peserta didik ditempatkan dalam kelompok belajar yang siswanya memiliki kemampuan heterogen. Siswa saling membantu sesama anggota kelompoknya. Semua siswa akan aktif dalam mengikuti pembelajaran. Siswa akan secara aktif berusaha untuk memahami materi pelajaran IPA. Siswa yang mengalami kendala dalam pembelajaran akan diberikan bantuan secara individu oleh teman kelompoknya maupun guru. Kegiatan pembelajaran dengan model TAI tentu akan menjadikan semua siswa mampu memahami materi pelajaran dengan baik. Harapan dari penerapan model TAI ini dapat memberikan dampak positif dan meningkat motivasi peserta didik dalam kegiatan pembelajaran. Untuk mengetahui signifikansi pengaruh model pembelajaran TAI terhadap prestasi belajar IPA diajukan Hipotesis sebagai berikut: (1) terdapat perbedaan hasil belajar IPA antara siswa yang dibelajarkan dengan model pembelajaran team assisted individualization dan siswa yang dibelajarkan dengan model pembelajaran konvensional; (2) terdapat perbedaan hasil belajar IPA antara siswa yang memiliki motivasi belajar tinggi dan siswa yang memiliki motivasi belajar rendah; (3) terdapat pengaruh interaksi model pembelajaran yang diterapkan dengan motivasi belajar terhadap hasil belajar IPA. 


\section{B. METODE PENELITIAN}

Penelitian ini menggunakan rancangan nonequivalent post test only control group design. Rancangan penelitian disajikan pada tabel 1 berikut:

\begin{tabular}{l|c|c}
\hline \multicolumn{1}{c|}{ Kelompok } & Perlakuan & Post Tes \\
\hline Eksperimen & $\mathrm{X}_{1}$ & $\mathrm{O}_{1}$ \\
\hline Kontrol & $\mathrm{X}_{2}$ & $\mathrm{O}_{2}$ \\
\hline
\end{tabular}

Rancangan analisis penelitian ini adalah ANAVA dua jalur (faktorial 2x2). Faktor pemilahnya adalah variabel moderator motivasi belajar siswa. Adapun rancangan analisis ANAVA dua jalur disajikan pada tabel 2.

\begin{tabular}{|c|c|c|}
\hline Motivasi Belajar & $\mathbf{A}_{1}$ & $\mathbf{A}_{2}$ \\
\hline $\mathrm{B}_{1}$ & $\mathrm{~A}_{1} \mathrm{~B}_{1}$ & $\mathrm{~A}_{2} \mathrm{~B}_{1}$ \\
\hline B2 & $\mathrm{A}_{1} \mathrm{~B}_{2}$ & $\mathrm{~A}_{2} \mathrm{~B}_{2}$ \\
\hline
\end{tabular}

Analisis yang digunakan untuk menghitung kesetaraan kelompok adalah ANAVA satu jalur dengan langkah-langkah sebagai berikut: (1) Menghitung Jumlah Kuadrad Total ( $\mathrm{JK}_{\text {tot }}$ ); (2) Menghitung Jumlah Kuadrad Antar Kelompok ( $\mathrm{JK}_{\text {antar }}$ ); (3) Menghitunng Jumlah Kuadrad Dalam Kelompok ( $\left.\mathrm{JK}_{\mathrm{dal}}\right)$; (4) Menghitung Rerata Jumlah Kuadrat Antar Kelompok $\left(\mathrm{RJK}_{\text {antar }}\right)$; (5) Menghitung Rerata Jumlah Kuadrat Dalam Kelompok $\left(\mathrm{RJK}_{\text {dal }}\right)$; (6) Menghitung harga $\mathrm{F}_{\text {hitung; }}$; (7) Bandingkan $\mathrm{F}_{\text {hitung }}$ dan $\mathrm{F}_{\text {tabel }}$ dengan db pembilang (a-1) dan db penyebut (N-1) (Koyan, 2012).

Data yang dikumpulkan dalam penelitian ini adalah data mengenai hasil belajar IPA siswa dan motivasi belajar IPA. Data hasil belajar dikumpulkan dengan menggunakan teknik tes hasil belajar. Data motivasi belajar dikumpulkan dengan menggunakan teknik kuesioner motivasi belajar. Pemberian tes ini dimaksudkan untuk mengungkap keseluruhan indikator yang merupakan bagian integral yang bersifat holistik pada setiap variabel penelitian. Metode pengumpulan data penelitian ini menggunakan tes, yaitu tes hasil belajar IPA. Motivasi belajar merupakan hasil pengukuran dalam bentuk skor yang didasarkan pada respon terhadap butir-butir kuesioner motivasi belajar yang dikembangkan oleh peneliti. Pola kuesioner mengikuti pola likert yang terdiri dari lima pilihan jawaban. Instrumen penelitian sebelum digunakan diadakan validasi expert oleh dua orang ahli, dan validasi empirik. Data yang diperoleh dari uji coba instrumen dianalisis validitas, reliabilitas, daya beda, dan tingkat kesukarannya (Koyan, 2012). Analisis deskriptif dilakukan untuk mengetahui tinggi rendahnya hasil belajar IPA. Metode analisis deskriptif kuantitatif adalah suatu cara pengolahan data yang dilakukan dengan cara menyusun secara sistematis dalam bentuk angka-angka atau persentase, mengenai suatu objek yang diteliti sehingga diperoleh kesimpulan umum. Analisis deskriptif dilakukan terhadap nilai rata-rata, modus, median, dan standar deviasi. Sebelum dilakukan uji hipotesis, terlebih dahulu dilakukan uji persyaratan analisis terhadap data hasil penelitian. Uji persyaratan analisis ini dilakukan untuk memperoleh fakta apakah data memenuhi persyaratan homogenitas varian dan normalitas sebaran (Irianto, 2010). Uji hipotesis menggunakan formula Anava $\mathrm{AB}$ (two way anova).

\section{HASIL DAN PEMBAHASAN}

1. Deskripsi Umum Data Hasil Penelitian

a) Deskripsi data hasil belajar IPA siswa pada kelompok eksperimen $\left(\mathrm{A}_{1}\right)$ :

Data hasil belajar IPA terhadap 21 orang siswa pada kelompok eksperimen, menunjukkan bahwa skor tertinggi $=28$, skor terendah $=14$, rentangan $=14$. Selanjutnya nilai mean $(\mathrm{M})=22,00$, median $(\mathrm{Md})=$ 22,74 , dan modus $(\mathrm{Mo})=24,50$, dan standar deviasi $(\mathrm{s})=4,28$. Distribusi frekuensi hasil belajar IPA pada kelompok eksperimen disajikan pada Tabel 3.

\begin{tabular}{c|c|c|c|c}
\hline Kelas Interval & Nilai Tengah & $\mathbf{F}_{\text {absolut }}$ & $\mathbf{F}_{\text {kumulatif }}$ & $\mathbf{F}_{\text {relatif }}(\boldsymbol{\%})$ \\
\hline $14-16$ & 15 & 2 & 2 & 9,52 \\
\hline $17-19$ & 18 & 4 & 6 & 19,05 \\
\hline $20-22$ & 21 & 4 & 10 & 19,05 \\
\hline $23-25$ & 24 & 6 & 16 & 28,57 \\
\hline $26-28$ & 27 & 5 & 21 & 23,81 \\
\hline Total & & 21 & - & 100 \\
\hline
\end{tabular}


Berdasarkan diatas, rata-rata hasil belajar IPA pada kelompok eksperimen berada pada interval 20-22, dengan frekuensi absolut 4 atau sebesar $19,05 \%$.

Kualitas variabel hasil belajar IPA dapat diketahui engan skor rata-rata hasil belajar IPA siswa dikonversikan dengan menggunakan kriteria rata-rata ideal $\left(\mathrm{M}_{\mathrm{i}}\right)$ dan standar deviasi ideal $\left(\mathrm{SD}_{\mathrm{i}}\right)$. Berdasarkan perhitungan $\mathrm{M}_{\mathrm{i}}$ dan $\mathrm{SD}_{\mathrm{i}}$ maka diperoleh hasil konversi seperti pada tabel 4:

\begin{tabular}{c|c}
\hline Rentang Skor & Klasifikasi \\
\hline $22,5 \leq \dot{\mathrm{x}} \leq 30$ & Sangat Baik \\
\hline $17,5 \leq \dot{\mathrm{x}}<22,5$ & Baik \\
\hline $12,5 \leq \dot{\mathrm{x}}<17,5$ & Cukup \\
\hline $7,5 \leq \dot{\mathrm{x}}<12,5$ & Tidak Baik \\
\hline $0,0 \leq \dot{\mathrm{x}}<7,5$ & Sangat Tidak Baik \\
\hline
\end{tabular}

Skor rata-rata hasil belajar IPA siswa kelompok eksperimen (X) adalah 22,00. Berdasarkan hasil konversi, dapat dinyatakan bahwa hasil belajar IPA siswa kelompok eksperimen termasuk dalam kategori baik.

b) Deskripsi data hasil belajar IPA siswa pada kelompok kontrol $\left(\mathrm{A}_{2}\right)$ :

Data hasil belajar IPA terhadap 21 orang siswa pada kelompok kontrol, menunjukkan bahwa skor tertinggi $=25$, skor terendah $=13$, rentangan $=12$. Nilai mean $(M)=19,62$, median $(\mathrm{Md})=18,74$, dan modus $(\mathrm{Mo})=$ 17,90 , dan standar deviasi $(\mathrm{s})=3,29$.

Distribusi frekuensi hasil belajar IPA pada kelompok kontrol disajikan pada Tabel 5.

\begin{tabular}{c|c|c|c|c}
\hline $\begin{array}{c}\text { Kelas } \\
\text { Interval }\end{array}$ & $\begin{array}{c}\text { Nilai } \\
\text { Tengah }\end{array}$ & $\mathbf{F}_{\text {absolut }}$ & $\mathbf{F}_{\text {kumulatif }}$ & $\begin{array}{c}\mathbf{F}_{\text {relatif }} \\
(\boldsymbol{\%})\end{array}$ \\
\hline $13-15$ & 14 & 3 & 3 & 14,29 \\
\hline $16-18$ & 17 & 7 & 10 & 33,33 \\
\hline $19-21$ & 20 & 6 & 16 & 28,57 \\
\hline $22-24$ & 23 & 3 & 19 & 14,29 \\
\hline $25-26$ & 25 & 2 & 21 & 9,52 \\
\hline Total & & 21 & - & 100 \\
\hline
\end{tabular}

Rata-rata hasil belajar IPA pada kelompok kontrol berada pada interval 19-21, dengan frekuensi absolut 6 atau sebesar $28,57 \%$.

Kualitas variabel hasil belajar IPA dapat diketahui dengan skor rata-rata hasil belajar IPA siswa dikonversikan dengan menggunakan kriteria rata-rata ideal $\left(\mathrm{M}_{\mathrm{i}}\right)$ dan standar deviasi ideal $\left(\mathrm{SD}_{\mathrm{i}}\right)$. Skor ratarata hasil belajar IPA siswa kelompok eksperimen adalah 19,62. Berdasarkan hasil konversi pada tabel 4 dapat dinyatakan bahwa hasil belajar IPA siswa kelompok kontrol termasuk dalam kategori baik.

c) Deskripsi data hasil belajar IPA kelompok siswa yang memiliki motivasi belajar tinggi $\left(B_{1}\right)$ :

Data hasil belajar IPA terhadap 22 orang siswa pada kelompok siswa yang memiliki motivasi belajar tinggi, menunjukkan bahwa skor tertinggi $=28$, skor terendah $=13$, rentangan $=15$. Nilai mean $(\mathbf{M})=21,64$, median $(\mathrm{Md})=22,10$, dan modus $(\mathrm{Mo})=23,75$, dan standar deviasi $(\mathrm{s})=4,52$.

Distribusi frekuensi hasil belajar IPA pada kelompok siswa yang memiliki motivasi belajar tinggi disajikan pada Tabel 6.

\begin{tabular}{c|c|c|c|c}
\hline $\begin{array}{c}\text { Kelas } \\
\text { Interval }\end{array}$ & $\begin{array}{c}\text { Nilai } \\
\text { Tengah }\end{array}$ & $\mathbf{F}_{\text {absolut }}$ & $\mathbf{F}_{\text {kumulatif }}$ & $\begin{array}{c}\mathbf{F}_{\text {relatif }} \\
(\mathbf{\%})\end{array}$ \\
\hline $13-15$ & 14 & 3 & 3 & 13,64 \\
\hline $16-18$ & 17 & 4 & 7 & 18,18 \\
\hline $19-21$ & 20 & 3 & 10 & 13,64 \\
\hline $22-24$ & 23 & 5 & 15 & 22,73 \\
\hline $25-27$ & 26 & 4 & 19 & 18,18 \\
\hline $28-30$ & 29 & 3 & 22 & 13,64 \\
\hline Total & & 22 & - & 100 \\
\hline
\end{tabular}

Berdasarkan Tabel diatas, rata-rata hasil belajar IPA pada kelompok siswa yang memiliki motivasi belajar tinggi berada pada interval 22-24, dengan frekuensi absolut 5 atau sebesar 22,73\%. Dengan skor rata-rata hasil belajar IPA siswa kelompok siswa yang memiliki motivasi belajar tinggi adalah 21,64. Berdasarkan 
hasil konversi pada tabel 4 dapat disimpulkan bahwa hasil belajar IPA kelompok siswa yang memiliki motivasi belajar tinggi termasuk dalam kategori baik.

d) Deskripsi data hasil belajar IPA kelompok siswa yang memiliki motivasi belajar rendah $\left(\mathrm{B}_{2}\right)$ :

Data hasil belajar IPA 20 orang peserta didik pada kelompok siswa yang memiliki motivasi belajar rendah, menunjukkan bahwa skor tertinggi $=25$, skor terendah $=14$, rentangan $=11$. Nilai mean $(M)=19,90$, median $(\mathrm{Md})=21,08$, dan modus $(\mathrm{Mo})=19,10$, dan standar deviasi $(\mathrm{s})=3,09$.

Distribusi frekuensi hasil belajar IPA pada kelompok siswa yang memiliki motivasi belajar rendah disajikan pada Tabel 7.

\begin{tabular}{c|c|c|c|c}
\hline $\begin{array}{c}\text { Kelas } \\
\text { Interval }\end{array}$ & $\begin{array}{c}\text { Nilai } \\
\text { Tengah }\end{array}$ & $\mathbf{F}_{\text {absolut }}$ & $\mathbf{F}_{\text {kumulatif }}$ & $\begin{array}{c}\mathbf{F}_{\text {relatif }} \\
(\boldsymbol{\%})\end{array}$ \\
\hline $13-15$ & 14 & 2 & 2 & 10,00 \\
\hline $16-18$ & 17 & 6 & 8 & 30,00 \\
\hline $19-21$ & 20 & 7 & 15 & 35,00 \\
\hline $22-24$ & 23 & 3 & 18 & 15,00 \\
\hline $25-27$ & 26 & 2 & 20 & 10,00 \\
\hline Total & & 20 & - & 100 \\
\hline
\end{tabular}

Rata-rata hasil belajar IPA pada kelompok siswa yang memiliki motivasi belajar rendah berada pada interval 19-21, dengan frekuensi absolut 7 atau sebesar 35\%. Selanjutnya rata-rata hasil belajar IPA kelompok siswa yang memiliki motivasi belajar rendah adalah 19,90.

Berdasarkan hasil konversi pada tabel 4, dapat dinyatakan bahwa hasil belajar IPA kelompok siswa yang memiliki motivasi belajar rendah termasuk dalam kategori baik.

e) Deskripsi data hasil belajar IPA kelompok eksperimen yang memiliki motivasi belajar tinggi $\left(A_{1} B_{1}\right)$ : Data hasil belajar IPA 11 siswa pada kelompok eksperimen yang memiliki motivasi belajar tinggi, menunjukkan bahwa skor tertinggi $=28$, skor terendah $=22$, rentangan $=6$. Nilai mean $(M)=25,27$, median $(\mathrm{Md})=22,50$, dan modus $(\mathrm{Mo})=26,90$, dan standar deviasi $(\mathrm{s})=2,28$. Distribusi frekuensi hasil belajar IPA pada kelompok eksperimen yang memiliki motivasi belajar tinggi disajikan pada Tabel 8 .

\begin{tabular}{c|c|c|c|c}
\hline $\begin{array}{c}\text { Kelas } \\
\text { Interval }\end{array}$ & $\begin{array}{c}\text { Nilai } \\
\text { Tengah }\end{array}$ & $\mathbf{F}_{\text {absolut }}$ & $\mathbf{F}_{\text {kumulatif }}$ & $\begin{array}{c}\mathbf{F}_{\text {relatif }} \\
(\boldsymbol{\%})\end{array}$ \\
\hline $21-22$ & 21,50 & 1 & 1 & 9,09 \\
\hline $23-24$ & 23,50 & 3 & 4 & 27,27 \\
\hline $25-26$ & 25,50 & 3 & 7 & 27,27 \\
\hline $27-28$ & 27,50 & 4 & 11 & 36,36 \\
\hline Total & & 11 & - & 100 \\
\hline
\end{tabular}

Nilai rata-rata hasil belajar IPA pada kelompok eksperimen yang memiliki motivasi belajar tinggi berada pada interval 25-26, dengan frekuensi absolut 3 atau sebesar 27,27\%. Skor rata-rata hasil belajar IPA siswa kelompok eksperimen yang memiliki motivasi belajar tinggi adalah 25,27. Berdasarkan hasil konversi pada tabel 4, dapat disimpulkan bahwa hasil belajar IPA kelompok eksperimen yang memiliki motivasi belajar tinggi termasuk dalam kategori sangat baik.

f) Deskripsi data hasil belajar IPA kelompok eksperimen yang memiliki motivasi belajar rendah $\left(A_{1} B_{2}\right)$ : Data hasil belajar IPA 10 siswa pada kelompok eksperimen yang memiliki motivasi belajar rendah menunjukkan bahwa skor tertinggi $=23$, skor terendah $=14$, rentangan $=9$. Nilai mean $(M)=18,40$, median $(\mathrm{Md})=16,50$, dan modus $(\mathrm{Mo})=16,83$, dan standar deviasi $(\mathrm{s})=2,27$. Distribusi frekuensi hasil belajar IPA pada kelompok eksperimen yang memiliki motivasi belajar rendah disajikan pada Tabel 9.

\begin{tabular}{c|c|c|c|c}
\hline $\begin{array}{c}\text { Kelas } \\
\text { Interval }\end{array}$ & $\begin{array}{c}\text { Nilai } \\
\text { Tengah }\end{array}$ & $\mathbf{F}_{\text {absolut }}$ & $\mathbf{F}_{\text {kumulatif }}$ & $\begin{array}{c}\mathbf{F}_{\text {relatif }} \\
(\boldsymbol{\%})\end{array}$ \\
\hline $13-15$ & 14 & 2 & 2 & 20,00 \\
\hline $16-18$ & 17 & 4 & 6 & 40,00 \\
\hline $19-21$ & 20 & 3 & 9 & 30,00 \\
\hline $22-24$ & 23 & 1 & 10 & 10,00 \\
\hline Total & & 10 & - & 100 \\
\hline
\end{tabular}


Rata-rata hasil belajar IPA pada kelompok eksperimen yang memiliki motivasi belajar rendah berada pada interval 16-18, dengan frekuensi absolut 4 atau sebesar $40 \%$. Skor rata-rata hasil belajar IPA kelompok eksperimen yang memiliki motivasi belajar rendah adalah 18,40. Berdasarkan hasil konversi pada tabel 4, dapat dinyatakan bahwa hasil belajar IPA kelompok eksperimen yang memiliki motivasi belajar rendah termasuk dalam kategori baik.

g) Deskripsi data hasil belajar IPA kelompok kontrol yang memiliki motivasi belajar tinggi $\left(A_{2} B_{1}\right)$ :

Data hasil belajar IPA terhadap 11 siswa pada kelompok kontrol yang memiliki motivasi belajar tinggi menunjukkan bahwa skor tertinggi $=23$, skor terendah $=13$, rentangan $=10$. Nilai mean $(M)=18,00$, median $(\mathrm{Md})=17,00$, dan modus $(\mathrm{Mo})=16,70$, dan standar deviasi $(\mathrm{s})=2,93$. Distribusi frekuensi hasil belajar IPA pada kelompok kontrol yang memiliki motivasi belajar tinggi disajikan pada Tabel 10.

\begin{tabular}{c|c|c|c|c}
\hline $\begin{array}{c}\text { Kelas } \\
\text { Interval }\end{array}$ & $\begin{array}{c}\text { Nilai } \\
\text { Tengah }\end{array}$ & $\mathbf{F}_{\text {absolut }}$ & $\mathbf{F}_{\text {kumulatif }}$ & $\begin{array}{c}\mathbf{F}_{\text {relatif }} \\
(\boldsymbol{\%})\end{array}$ \\
\hline $13-15$ & 14 & 3 & 3 & 27,27 \\
\hline $16-18$ & 17 & 5 & 8 & 45,45 \\
\hline $19-21$ & 20 & 2 & 10 & 18,18 \\
\hline $22-24$ & 23 & 1 & 11 & 9,09 \\
\hline Total & & 11 & - & 100 \\
\hline
\end{tabular}

Rata-rata hasil belajar IPA pada kelompok kontrol yang memiliki motivasi belajar tinggi berada pada interval 16-18, dengan frekuensi absolut 5 atau sebesar 45,45\%. Skor rata-rata hasil belajar IPA siswa kelompok kontrol yang memiliki motivasi belajar tinggi adalah 18,00. Berdasarkan hasil konversi pada tabel 4, dapat dinyatakan bahwa hasil belajar IPA kelompok kontrol yang memiliki motivasi belajar tinggi termasuk dalam kategori baik.

h) Deskripsi data hasil belajar IPA kelompok kontrol yang memiliki motivasi belajar rendah $\left(A_{2} B_{2}\right)$ : Data hasil belajar IPA terhadap 10 orang pada kelompok kontrol yang memiliki motivasi belajar rendah, menunjukkan bahwa skor tertinggi $=25$, skor terendah $=17$, rentangan $=8$. Nilai mean $(M)=21,40$, median $(\mathrm{Md})=20,75$, dan modus $(\mathrm{Mo})=20$, dan standar deviasi $(\mathrm{s})=2,80$. Distribusi frekuensi hasil belajar IPA pada kelompok kontrol yang memiliki motivasi belajar rendah disajikan pada Tabel 11.

\begin{tabular}{c|c|c|c|c}
\hline $\begin{array}{c}\text { Kelas } \\
\text { Interval }\end{array}$ & $\begin{array}{c}\text { Nilai } \\
\text { Tengah }\end{array}$ & $\mathbf{F}_{\text {absolut }}$ & $\mathbf{F}_{\text {kumulatif }}$ & $\begin{array}{c}\mathbf{F}_{\text {relatif }} \\
(\boldsymbol{\%})\end{array}$ \\
\hline $16-18$ & 17 & 2 & 2 & 20 \\
\hline $19-21$ & 20 & 4 & 6 & 40 \\
\hline $22-24$ & 23 & 2 & 8 & 20 \\
\hline $25-27$ & 26 & 2 & 10 & 20 \\
\hline Total & & 10 & - & 100 \\
\hline
\end{tabular}

Rata-rata hasil belajar IPA pada kelompok kontrol yang memiliki motivasi belajar rendah berada pada interval 19-21, dengan frekuensi absolut 4 atau sebesar 40\%. Skor rata-rata hasil belajar IPA siswa kelompok kontrol yang memiliki motivasi belajar rendah adalah 21,40. Berdasarkan hasil konversi pada tabel 4, dapat dinyatakan bahwa hasil belajar IPA kelompok kontrol yang memiliki motivasi belajar rendah termasuk dalam kategori baik.

\section{Uji Prasyarat}

Uji normalitas data dilakukan terhadap delapan kelompok data. Kelompok data yang diuji normalitasnya adalah sebagai berikut:

$\mathrm{A}_{1} \quad:$ Kelompok Eksperimen

$\mathrm{A}_{2} \quad$ : Kelompok Kontrol

$\mathrm{B}_{1} \quad$ : Kelompok eksperimen dan kontrol yang memiliki motivasi belajar tinggi.

$\mathrm{B}_{2} \quad:$ Kelompok eksperimen dan kontrol yang memiliki motivasi belajar rendah.

$\mathrm{A}_{1} \mathrm{~B}_{1} \quad$ : Kelompok eksperimen yang memiliki motivasi belajar tinggi.

$\mathrm{A}_{1} \mathrm{~B}_{2} \quad$ : Kelompok eksperimen yang memiliki motivasi belajar rendah.

$\mathrm{A}_{2} \mathrm{~B}_{1} \quad$ : Kelompok kontrol yang memiliki motivasi belajar tinggi.

$\mathrm{A}_{2} \mathrm{~B}_{2} \quad$ : Kelompok kontrol yang memiliki motivasi belajar rendah. 
Ringkasan hasil uji normalitas dengan menggunakan statistik Kolmogorov-Smirnov dan Shapiro-Wilk disajikan pada Tabel 12 .

\begin{tabular}{c|c|c|c|c|c|c|c|c}
\hline \multicolumn{10}{c}{ Uji Normalitas } \\
\hline \multirow{2}{*}{} & Kelompok & \multicolumn{2}{|c}{ Kolmogorov-Smirnov } & \multicolumn{4}{|c}{ Shapiro-Wilk } & Ket \\
\cline { 3 - 9 } & & Statistic & Df & Sig. & Statistic & Df & Sig. & Normal \\
\hline \multirow{4}{*}{ Skor } & $\mathrm{A}_{1}$ &, 116 & 21 &, $200^{*}$ &, 951 & 21 &, 356 & Normal \\
\cline { 2 - 9 } & $\mathrm{A}_{2}$ &, 165 & 21 &, 141 &, 957 & 21 &, 463 & Normal \\
\cline { 2 - 9 } & $\mathrm{B}_{1}$ &, 153 & 22 &, 197 &, 943 & 22 &, 226 & Normal \\
\cline { 2 - 9 } & $\mathrm{B}_{2}$ &, 130 & 20 &, $200^{*}$ &, 962 & 20 &, 589 & Normal \\
\hline & $\mathrm{A}_{1} \mathrm{~B}_{1}$ &, 204 & 11 &, $200^{*}$ &, 884 & 11 &, 116 & Normal \\
\hline & $\mathrm{A}_{1} \mathrm{~B}_{2}$ &, 159 & 10 &, $200^{*}$ &, 970 & 10 &, 892 & Normal \\
\hline & $\mathrm{A}_{2} \mathrm{~B}_{1}$ &, 227 & 11 &, 117 &, 930 & 11 &, 415 & Normal \\
\hline & $\mathrm{A}_{2} \mathrm{~B}_{2}$ &, 157 & 10 &, $200^{*}$ &, 936 & 10 &, 511 & Normal \\
\hline
\end{tabular}

Dapat diketahui bahwa semua nilai signifikansi berada di atas 0,05 untuk statistik Kolmogorov-Smirnov dan Shapiro-Wilk. Berdasarkan kriteria uji normalitas, data terdistribusi normal jika angka signifikansi yang dihasilkan lebih besar dari 0,05 . Hasil perhitungan menunjukkan bahwa sebaran data pada semua unit analisis berdistribusi normal

Hasil uji homogenitas varians dapat diringkas pada Tabel 13.

\begin{tabular}{c|c|c|c|c|c|c}
\hline Sampel & Dk & $\mathbf{1 / d k}$ & $\mathbf{s}^{2}$ & $\mathbf{d k . s}^{2}$ & log.s $^{2}$ & $(\mathbf{d k})$ log.s \\
\hline $\mathrm{A}_{1} \mathrm{~B}_{1}$ & 10 & 0,10 & 5,22 & 52,18 & 0,72 & 7,18 \\
\hline $\mathrm{A}_{1} \mathrm{~B}_{2}$ & 9 & 0,11 & 7,38 & 66,40 & 0,87 & 7,81 \\
\hline $\mathrm{A}_{2} \mathrm{~B}_{1}$ & 10 & 0,10 & 8,60 & 86,00 & 0,93 & 9,34 \\
\hline $\mathrm{A}_{2} \mathrm{~B}_{2}$ & 9 & 0,11 & 7,82 & 70,40 & 0,89 & 8,04 \\
\hline Total & 38 & 0,42 & & 274,98 & & 32,37 \\
\hline
\end{tabular}

Untuk taraf signifikansi $5 \%$ dan $\mathrm{dk}=\mathrm{k}-1=4-1=3 ; x^{2}=7,815$. Dari hasil perhitungan diperoleh $x^{2}=0,66$, sedangkan $x_{\text {tabel }}^{2}=7,815$, sehingga $x^{2}<x_{\text {tabel }}^{2}$. Ini berarti, $\mathrm{H}_{1}$ ditolak dan $\mathrm{H}_{0}$ diterima. Dapat disimpulkan, data hasil belajar IPA siswa berasal dari populasi yang homogen.

Berdasarkan perhitungan uji prasyarat, data hasil belajar IPA telah memenuhi persyaratan analisis, yaitu data berdistribusi normal dan varians antar kelompok homogen. Oleh karena itu, pengujian hipotesis dengan menggunakan ANAVA dua jalur dapat dilanjutkan.

\section{Pengujian Hipotesis}

Ringkasan hasil ANAVA dua jalur disajikan pada tabel 14.

\begin{tabular}{c|c|c|c|c|c}
\hline Sumber Variasi & JK & Db & RJK & F & Ftab \\
\hline A & 59,53 & 1 & 59,53 & 8,22 & $5 \%$ \\
\hline B & 31,59 & 1 & 31,59 & 4,36 & 4,10 \\
\hline Inter AB & 276,38 & 1 & 276,38 & 38,17 & 4,10 \\
\hline Dal & 274,98 & 38 & 7,24 & & 4,10 \\
\hline Jumlah & 642,48 & & & & \\
\hline
\end{tabular}

Berdasarkan ringkasan hasil ANAVA dua jalur yang tercantum pada tabel 13 dapat disimpulkan hal-hal sebagai berikut. Hipotesis pertama diperoleh hasil bahwa kelompok siswa yang dibelajarkan dengan model pembelajaran team assisted individualization $\left(\mathrm{A}_{1}\right)$ memiliki rata-rata hasil belajar IPA sebesar 22,00. Sedangkan, kelompok siswa yang dibelajarkan dengan model pembelajaran konvensional $\left(\mathrm{A}_{2}\right)$ memiliki rata-rata hasil belajar sebesar 19,62.

Berdasarkan hal tersebut, skor rata-rata hasil belajar IPA siswa yang dibelajarkan dengan model pembelajaran team assisted individualization lebih tinggi dibandingkan dengan siswa yang dibelajarkan dengan model pembelajaran konvensional.

Hasil uji hipotesis kedua menunjukkan bahwa terdapat perbedaan yang signifikan hasil belajar IPA antara siswa yang memiliki motivasi belajar tinggi dan siswa yang memiliki motivasi belajar rendah. Hasil belajar IPA siswa yang memiliki motivasi belajar tinggi lebih baik daripada hasil belajar IPA siswa yang memiliki motivasi 
belajar rendah. Hipotesis ketiga diketahui adanya perbedaan skor rata-rata hasil belajar IPA untuk setiap tingkat motivasi belajar. Dalam tingkat motivasi belajar tinggi, skor rata-rata hasil belajar IPA siswa yang dibelajarkan dengan model pembelajaran team assisted individualization lebih baik daripada hasil belajar IPA siswa yang dibelajarkan dengan model pembelajaran konvensional. Pada tingkat motivasi belajar rendah, skor rata-rata hasil belajar IPA siswa yang dibelajarkan dengan model pembelajaran konvensional lebih baik daripada hasil belajar IPA siswa yang dibelajarkan dengan model pembelajaran TAI.

\section{SIMPULAN DAN SARAN}

Berdasarkan hasil penelitian dan analisis data, adapun temuan dalam penelitian ini adalah sebagai berikut: 1) Terdapat perbedaan yang signifikan hasil belajar IPA antara siswa yang dibelajarkan dengan model pembelajaran TAI dan siswa yang dibelajarkan dengan model pembelajaran konvensional. Rata-rata hasil belajar siswa yang dibelajarkan dengan model pembelajaran pembelajaran TAI lebih tinggi daripada rata-rata hasil belajar IPA siswa yang dibelajarkan dengan pembelajaran konvensional; 2) Terdapat perbedaan yang signifikan hasil belajar IPA antara siswa yang memiliki motivasi belajar tinggi dan siswa yang memiliki motivasi belajar rendah. Rata-rata hasil belajar IPA siswa yang memiliki motivasi belajar tinggi lebih besar dari rata-rata hasil belajar IPA siswa yang memiliki motivasi belajar rendah; 3) Terdapat pengaruh interaksi yang signifikan antara model pembelajaran TAI dan motivasi belajar terhadap hasil belajar IPA siswa. Berdasarkan temuan di atas, dapat disimpulkan bahwa model pembelajaran TAI memiliki pengaruh yang signifikan terhadap hasil belajar IPA ditinjau dari motivasi belajar siswa kelas IV SD Inpres Cowaang Terang.

Saran yang dapat disampaikan berdasarkan penelitian yang telah dilakukan adalah: 1) Disarankan kepada guru-guru di sekolah dasar agar tidak hanya mementingkan aspek kognitif, tetapi juga dapat lebih berinovasi dalam pembelajaran dengan menerapkan suatu model pembelajaran yang inovatif yang relevan untuk dapat meningkatkan hasil belajar siswa; 2) Disarankan kepada siswa sekolah dasar agar lebih aktif dalam mengikuti pembelajaran dan terus mengembangkan pemahamannya dengan membangun sendiri pengetahuan tersebut melalui pemahaman serta dapat menerapkannya dalam kehidupan sehari-hari; 3) Disarankan bagi peneliti lain yang berminat untuk mengadakan penelitian lebih lanjut tentang model pembelajaran TAI dalam bidang IPA maupun bidang ilmu lainnya, agar memperhatikan kendala-kendala yang dialami dalam penelitian ini sebagai bahan pertimbangan untuk perbaikan dan penyempurnaan penelitian yang akan dilaksanakan.

\section{DAFTAR RUJUKAN}

[1] Irianto, Agus. 2010. Statistik: Konsep Dasar, Aplikasi, dan Pengembangannya. Jakarta: Kencana Prenada Media Group.

[2] Koyan, I Wayan. 2012. Statistik Pendidikan: Teknik Analisis Data Kuantitatif. Singaraja: Universitas Pendidikan Ganesha Press.

[3] Muhsam, J., dk. 2020. Penerapan model pembelajaran contextual teaching learning (CTL) pada materi gaya bagi siswa kelas 4 sekolah dasar. Jurnal Elementary. Vol. 3 No. 2 Juni 2020, hal. 53 - 57

[4] Slavin, Robert E. 2008. Cooperative Learning: Teori, Riset dan Praktik. Terjemahan Narulita Yusron. Cooperative Learning: Theory, Research and Practice. 2005. Bandung: Nusa Media.

[5] Trianto. 2012. Model Pembelajaran Terpadu: Konsep, Strategi, dan Implementasinya dalam Kurikulum Tingkat Satuan Pendidikan. Jakarta: Bumi Aksara.

[6] Trianto. 2014. Mendesain Model Pembelajaran Inovatif, Progresif, dan Kontekstual (Konsep, Landasan, dan Implementasinya pada Kurikulum 2013). Jakarta: PT Kharisma Putra Utama. ISBN 978-602-1186053

[7] Westport, Praeger. 2009. Handbook of Cooverative Learning: Inovasi Pengajaran dan Pembelajaran untuk Memacu Keberhasilan Siswa di Kelas. Terjemahan Shlomo Sharan. Handbook of Cooverative Learning Methods. 1999. Yogyakarta: Imperium.

[8] Zubaedi. 2011. Desain Pendidikan Karakter: Konsepsi dan Aplikasinya dalam Lembaga Pendidikan. Jakarta: Kencana Media Group 